\title{
Robustness of Self-Organised Systems to Changes in Behaviour: An Example from Real and Simulated Self- Organised Snail Aggregations
}

\author{
Richard Stafford', Gray A. Williams², Mark S. Davies ${ }^{3 *}$ \\ 1 Luton Institute of Research in Applied Natural Sciences, University of Bedfordshire, Luton, United Kingdom, 2 The Swire Institute of Marine Science and School of \\ Biological Sciences, The University of Hong Kong, Hong Kong, 3 Faculty of Applied Sciences, University of Sunderland, Sunderland, United Kingdom
}

\begin{abstract}
Group or population level self-organised systems comprise many individuals displaying group-level emergent properties. Current theory indicates that individual-level behaviours have an effect on the final group-level behaviour; that is, selforganised systems are sensitive to small changes in individual behaviour. Here we examine a self-organised behaviour in relation to environmentally-driven individual-level changes in behaviour, using both natural systems and computer simulations. We demonstrate that aggregations of intertidal snails slightly decrease in size when, owing to hotter and more desiccating conditions, individuals forage for shorter periods - a seemingly non-adaptive behaviour for the snails since aggregation reduces desiccation stress. This decrease, however, only occurs in simple experimental systems (and simulations of these systems). When studied in their natural and more complex environment, and simulations of such an environment, using the same reduced foraging time, no difference in aggregation behaviour was found between hot and cool days. These results give an indication of how robust self-organised systems are to changes in individual-level behaviour. The complexity of the natural environment and the interactions of individuals with this environment, therefore, can result in self-organised systems being more resilient to individual-level changes than previously assumed.
\end{abstract}

Citation: Stafford R, Williams GA, Davies MS (2011) Robustness of Self-Organised Systems to Changes in Behaviour: An Example from Real and Simulated SelfOrganised Snail Aggregations. PLoS ONE 6(7): e22743. doi:10.1371/journal.pone.0022743

Editor: Gonzalo G. de Polavieja, Cajal Institute, Consejo Superior de Investigaciones Científicas, Spain

Received March 23, 2011; Accepted July 4, 2011; Published July 28, 2011

Copyright: (C) 2011 Stafford et al. This is an open-access article distributed under the terms of the Creative Commons Attribution License, which permits unrestricted use, distribution, and reproduction in any medium, provided the original author and source are credited.

Funding: Funding supplied personally and by the authors' respective universities. The universities had no role in study design, data collection and analysis, decision to publish, or preparation of the manuscript. However, RS and MD who paid personally for travel - and therefore are funders - participated in study design, data collection and analysis, decision to publish, or preparation of the manuscript.

Competing Interests: The authors have declared that no competing interests exist.

* E-mail: mark.davies@sunderland.ac.uk

\section{Introduction}

Self-organised systems are frequently considered sensitive to changes in the individual-level behaviours of organisms that comprise the systems $[1,2]$. For example, studies on simulations of army ants have demonstrated that certain parameters, such as individual variability in direction of movement, greatly affect the colony's foraging efficiency, and that in nature, these 'parameters' or behaviours are optimally set to maximise foraging [1-5].

The rocky shore habitat experiences very clear environmental changes with the rise and fall of the tide, and species in this habitat are easy to study and manipulate in field or laboratory experiments. As a result, rocky shore species are ideal candidates to examine how environmental variables affect individual-level behaviours [6-8]. For example, increasing air temperature when mobile invertebrates are emersed results in decreased foraging times (as a result of greater desiccation stress) [e.g. 9,10], resulting in animals becoming inactive, often in groups, when the tide is out. Often, animals try to find shelter from the desiccating conditions associated with emersion, and can be found in cracks and crevices in the rock surface, or in aggregations [10]. Self-organisation of aggregation behaviour has been documented in species of highshore littorinid snails [11-13], and simulation models of these snails have been validated on data collected from natural shores [12]. This system, therefore, provides an excellent opportunity to test predictions on naturally-occurring changes in individual-level behaviour, and the resultant, group-level, self-organised distributions that form under different environmental conditions. In this study we test the effects of increased desiccation stress on the ability of snails to form aggregations, using natural systems (rocky shores on hot and cool days), simplified experimental treatments (artificial rock slabs with roofs to decrease desiccation stress), and computer simulations of the natural and experimental systems.

\section{Methods}

\section{Study system}

In Hong Kong, during the incoming tide, high-shore littorinid snails (Echinolittorina malaccana and E. radiata) move up the shore to feed in the awash zone (wet by the waves, but not submerged) $[10,12]$. As the tide retreats, the snails move back down the shore and form aggregations of 2 to $>50$ individuals as the rock surface dries [10,12]. Aggregations reduce desiccation [10] and this behaviour is important because snails can be emersed for $>24 \mathrm{~h}$ between tides that are high enough to wet them [10,12].

Snails show three simple behaviours that, when simulated, account for their distribution patterns. Firstly, if snails encounter another individual (by chance), then they can choose to stop and aggregate. Secondly, if snails encounter a crevice (a depression in the rock that they can enter), they can choose to remain in the 
crevice. Thirdly, snails can follow trails of mucus, laid previously by other individuals (of either species) on the substratum and which persist over tidal cycles. Using only these three 'rules', the simulated snails show the same spatial distribution patterns as real snails [12]. Aggregations, therefore, result from a process of selforganisation. Essentially aggregations arise from chance encounters with other individuals, but some of these chance encounters are facilitated by the following of mucus trails. Thus likely sites of large aggregations are where trails cross each other, or where trails cross crevices or other topographic features causing 'trail leaders' to slow or stop [12].

\section{Natural shore study}

The percentage of snails aggregating during an ebbing tide after high water was investigated at two shores on Hong Kong Island, Cape d'Aguilar $\left(22.3037^{\circ} \mathrm{N}, 114.2558^{\circ} \mathrm{E}\right)$ and Wah $\mathrm{Fu}$ $\left(22.2499^{\circ} \mathrm{N}, 114.1304^{\circ} \mathrm{E}\right)$, in August and September 2001. The percentage of snails in aggregations (aggregations defined after $[10,14,15]$ as $\geq 3$ individuals in direct physical contact with each other) was calculated in ten, randomly located, quadrats $\left(0.25 \mathrm{~m}^{2}\right)$ along a pre-determined 50-m stretch of shore. Sampling was repeated on three replicate days under two different sets of environmental conditions: Hot Days $(\mathrm{H}$, air temperature $300 \mathrm{~mm}$ above the rock surface was $>35^{\circ} \mathrm{C}$ ) and Cool Days $(\mathrm{C}$, temperature was $<28^{\circ} \mathrm{C}$ ). Other factors, such as wave action, were as similar as possible between the different days, although wave action was slightly lower at Cape d'Aguilar $(<100 \mathrm{~mm}$ high waves) than at Wah $\mathrm{Fu}(300-500 \mathrm{~mm}$, predominantly due to passing boat traffic). The order in which the samples were taken at each shore was randomly determined, with at least $48 \mathrm{~h}$ separating replicate sample days. Between sample days, snails were seen actively foraging during high tide, confirming that individuals moved between sample days. To confirm the assumed increase in desiccation stress on Hot as compared to Cool Days, cotton wool balls soaked in water $(n=5)$ were weighed before and after $1 \mathrm{~h}$ of emersion on the rock surface at Cape d'Aguilar on each of the replicate days, and the percentage water loss calculated.

\section{Semi-artificial environment study}

Although we attempted to minimise possible confounding effects such as wave action on different replicate days in the natural shore study, it is impossible to eliminate all possible confounds. To try to reduce such effects, a manipulative experiment was carried out on artificial substrata (marble rock slabs) on the shore at Cape d'Aguilar. The slabs created a simplified environment, with a flat rock surface and, prior to the setup of the experiment, no mucus trails. Slabs $(300 \times 300 \mathrm{~mm})$ were placed flat on the shore at the mean high, high water level (mean of the maximum tidal height at spring tides). To prevent snails from escaping, Tree Tanglefoot gum (Tanglefoot Company, Michigan, USA) was placed around the perimeter of the slabs [16].

Ten replicates of three treatments were randomly assigned to 30 slabs $\left(\sum n=3 \times 10=30\right)$. Ten slabs were shaded using a roof of aluminium foil wrapped around wire mesh (roof size $350 \times 350 \mathrm{~mm}$ ) supported $50 \mathrm{~mm}$ above the slab surface. The roof shaded the experimental area from direct sunlight and therefore lowered both temperature and desiccation. Ten slabs were procedural controls, consisting of a wire mesh roof (mesh size $7 \mathrm{~mm}$ ) not covered in foil, therefore having the same roof frame but no shading. The final treatment was an unmanipulated open treatment (the control), with no roof and therefore subject to direct sunlight.
During low water, 7 Echinolittorina malaccana and 8 E. radiata (representative of the population density of each species on the shore, all $\sim 6 \mathrm{~mm}$ in shell length) were placed on the slabs and allowed to attach by their foot or mucus holdfast. During high water, waves $(<100 \mathrm{~mm}$ in height) washed over the slabs for $>1 \mathrm{~h}$ and the snails were observed to move. The tide began to retreat just prior to midday, so air temperatures were high $\left(>35^{\circ} \mathrm{C}\right)$ when the plates dried and the snails stopped moving. Once all animals had stopped moving, the percentage of snails in aggregations on each slab was determined and slab surface temperature was measured with a K-type thermocouple (see [17] for details). Desiccation rates on each plate were estimated by measuring weight loss over $1 \mathrm{~h}$ of cotton wall balls soaked in water 1 cotton wool ball per plate) during mid-afternoon, after all snail movement had stopped.

\section{Computer simulation}

Overview. The simulation was based on that used in [12] and consists of a number of virtual snails that move around a virtual shore, based on realistic and statistically accurate movement patterns. During the retreating tide, snails cease their foraging in the awash zone and move down the shore where, if chance encounters with previously laid mucus trails occur, they may choose to follow the trails. Also if encounters with other snails occur, then they may choose to aggregate with these snails, and consequently stop moving. Decisions are time-based: each decision to trail-follow or aggregate is more likely to occur the longer the simulation runs. This time base is a proxy for dryness of the rock (which becomes more dry the longer it is exposed to air after the tide retreats). A simulation can last for one or more tidal cycles, each of which consists of individuals moving up the shore, foraging in the awash zone, and moving back down the shore. At the end of the simulation, the percentage of snails in aggregations is calculated.

Implementation of the simulation. The simulated rocky shore $\left(1 \mathrm{~m}^{2}\right)$ was divided into a grid of $5 \times 5 \mathrm{~mm}$ squares. Snails could move from one square to any of the eight neighbouring squares, giving an average distance between squares of $\sim 6 \mathrm{~mm}$ (accounting for the diagonal distance being further than the orthogonal), which was the length of an average snail. One timestep in the simulation was defined as the time taken for each snail to move from one grid square to a neighbouring grid square. The simulation normally lasted 400 timesteps for each simulated tidal cycle (equivalent to $3 \mathrm{~h}$ on a real shore). In most simulations, snails were prevented from moving off the top of the simulated shore by restricting upward movement directions, this typically only affected $<5 \%$ of snails in any given simulation [12]. Snails moving off the side of the simulated shore rejoined on the opposite side, moving in the same direction. Snails were able to leave the bottom of the simulated shore, and if they did so in the final tidal cycle of the simulation, they were not included in further analysis. Snails leaving the bottom of the shore in other tidal cycles rejoined the simulation at the bottom of the grid at the start of the next tidal simulation, with their horizontal positions randomly determined.

Simulated snails were initially randomly located in the lower 100 rows of the grid. At the start of each tidal cycle, each individual moved up the shore with an initial bearing of $0^{\circ}$. At each timestep a new bearing was obtained by summing the previous bearing with a randomly-generated angle from a normal distribution $\left(\right.$ mean $\left.=0^{\circ}, \mathrm{SD}=10^{\circ}\right)$. A bearing of $0^{\circ}$ was also applied at timesteps 10, 20, 40 and 80 to ensure simulated patterns were similar to observed patterns in that the snails moved upshore [12]. Once in the top 40 rows of the grid (the position of the snails during slack water at high tide while they are foraging in the awash 
zone) the randomly-generated angle was changed to give a more tortuous movement pattern $\left(\right.$ mean $\left.=0^{\circ}, \mathrm{SD}=100^{\circ}\right)$. As the tide retreated (from timestep $=250$ ), snails following the tide down the shore were initially given a bearing of $180^{\circ}$, and then the bearing was again modified by a random angle $\left(\right.$ mean $=0^{\circ}, \mathrm{SD}=10^{\circ}$ ). These bearings and angles mimicked real snail behaviour as they moved up and down the shore with the rise and fall of the tide $[10,12]$. Patterns of simulated individual movement have previously been shown not to be significantly different from real snails' movement patterns in terms of length of the trail and fractal dimensions of the trail $[10,11]$.

Decisions were made when snails encountered other snails, and when snails encountered the mucus trails of other snails. To simulate a decision, a random number (from a uniform distribution between 0 and 1) was compared to the probability threshold, $y$, which increased sigmoidally with the time of the simulation (to create a proxy for dryness of the rock):

$$
y=\frac{1}{1+e^{-a(t-b)}},
$$

where $t$ is the timestep, normally between 1 and 400, and values of parameters $a$ and $b$ control the probability of the decision occurring at a given timestep. These parameters were modified depending on the simulation (see Figure 1). If the random number was lower than the probability, then the decision to aggregate or trail-follow took place. The likelihood of trail following or aggregating, therefore, increased with the advancing number of timesteps of the simulation, but still depended on chance encounters with other snails or trails. Although aggregated snails were not moving, they could take part in further aggregation decisions if other snails encountered them - this may result in these aggregations increasing in size.

To simulate the observed effects of increased desiccation, the number of timesteps in some of the simulations was reduced from 400 to 350 . This simulated the behavioural response of snails which stop moving earlier in relation to increased desiccation stress and the drying of the rock surface. This reduction in time is indicative of the shorter foraging time experienced under hotter conditions, as measured in different treatments in the artificial environment experiment (see Results). To simulate differences in individual level behaviour as a result of increases in desiccation stress, in addition to the changes in the total number of timesteps, the behavioural rules of aggregation formation and trail following were also altered (Figure 1). This allowed decision outcomes of 'aggregate' and 'follow mucus trails' to occur with greater probability earlier in the simulation, since we predict that decisions made by the snails (although modelled as time-based) are related to the dryness of the rock surface [11]. Previous observations of snail movement at different rock surface temperatures indicated no change in speed of snail movement with temperature until just prior to the point when the snails stopped moving [10].

To provide simulation results to compare to the shore study, $1 \mathrm{~m}^{2}$ of shore was simulated with the same density of snails as recorded from the real shore (112 individuals $\mathrm{m}^{-2}$, based on mean snail densities in quadrats analysed in this study). Persistence of mucus trails has previously been shown to be important in determining the spatial and temporal patterns of snails on the shore and degradation of mucus trails during tidal cycles was modelled as per [12]:

$$
M_{t+1}=M_{t}\left(e^{-0.78}\right)
$$

where $M$ is the amount of mucus present in each $5 \times 5 \mathrm{~mm}$ grid square. To ensure the effects relating to persistence of mucus trails were incorporated into the simulation, each run of the simulation was repeated over three tidal cycles before results were collected, thus allowing simulation of mucus trails laid on the shore during previous movements of snails. A randomly selected area (a $500 \times 500 \mathrm{~mm}$ quadrat - equal in area to the shore study) of the simulated shore was then investigated. Since we randomly selected quadrats on the shore, crevice distribution varied between replicate quadrats, and, as crevice distribution can affect the proportion of snails aggregating (although not significantly, [12]),

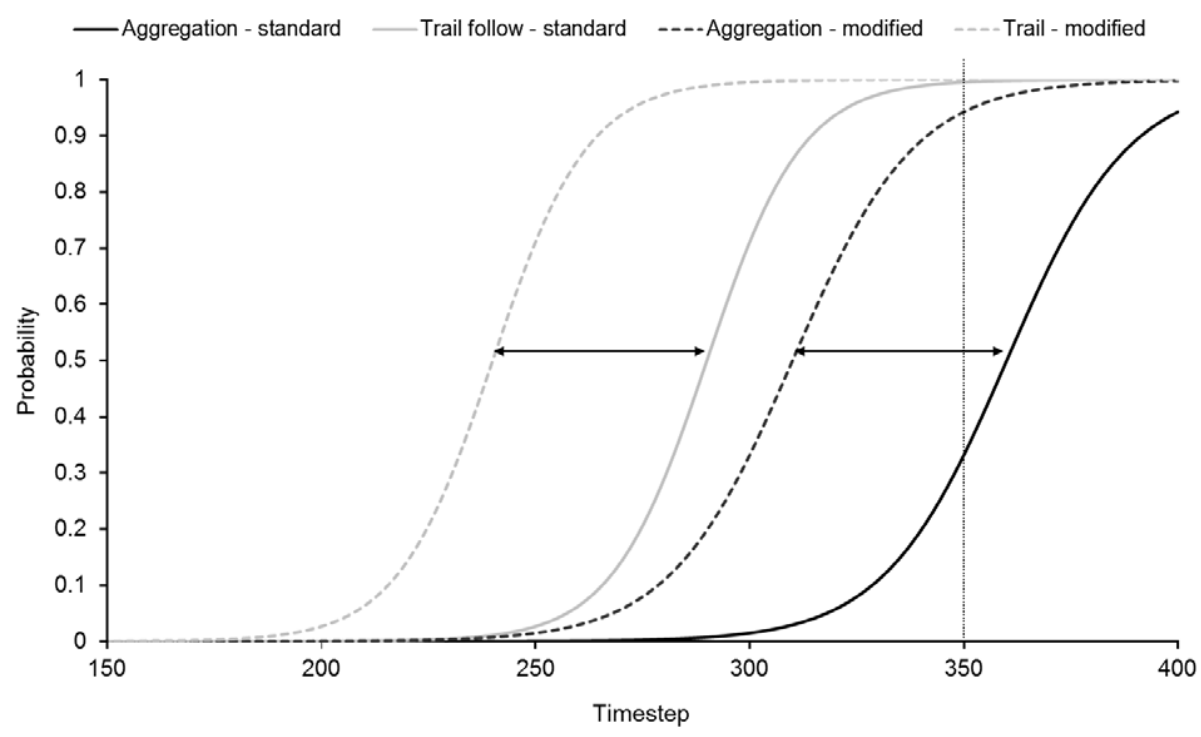

Figure 1. Probabilities of trail following or aggregating. The probability of trail following or aggregating given an encounter between two snails or a snail and a previously-laid mucus trail. Right of the arrows indicates 'standard' parameters for equation 1 as in [12]: trail following $a=0.9$, $b=290$, aggregation $a=0.7, b=360$. Left of the arrows indicates modified parameters used to indicate higher levels of desiccation stress: trail following $a=0.9, b=240$, aggregation $a=0.7, b=310$. The vertical line indicates when snails stop moving in hotter, more desiccating conditions. doi:10.1371/journal.pone.0022743.g001 
we simulated all shores to have no crevices. Thus, our simulation results would not be expected to show exact matches to the observed data from real snails, but should be indicative of trends caused by changing physical factors.

To compare the simulation with the semi-artificial environment study, we simulated a shore of $300 \times 300 \mathrm{~mm}$ - the same size as the marble slabs used in the semi-artificial environment study. We prevented simulated snails moving outside these dimensions by preventing movement off the edge until a new direction within the $300 \times 300 \mathrm{~mm}$ area was established, as would occur with real snails that were restricted to moving solely within the artificial environment. Since the snails were already in the awash zone when first immersed, and could not move fully down the shore with the retreating tide, the times of the simulations were restricted to 200 timesteps (from timestep 150 to timestep 350) for the low desiccation (shaded) treatment and 175 timesteps (150 to 325) for the open treatment.

For both simulations of the natural shore study and the semiartificial environment study three sets of simulations were conducted:

1) simulations over the full duration of the model (400 timesteps for the shore study and 200 for the semi-artificial environment study);

2) simulations over the reduced length model (350 timesteps for the shore study and 175 for the semi-artificial environment study) but with no changes to the behavioural rules of the individuals;

3) simulations over the reduced length model (350 timesteps for the shore study and 175 for the semi-artificial environment study) but with changes to the individual's behavioural rules as indicated in Figure 1.

\section{Results}

\section{Natural shore study}

Desiccation rate differed significantly between the different temperature conditions (mean $\pm \mathrm{SE} \mathrm{n}=15$, desiccation rate $=71 \pm 1.4 \% \mathrm{~h}^{-1}$ during Hot Days compared to $51 \pm$ $0.7 \% \mathrm{~h}^{-1}$ during Cool Days), although significant differences were also observed between replicate days within the same conditions (Table 1). There were, however, no significant differences in the percentage occurrence of aggregation behaviour between Hot or Cool Days or replicate days within conditions at
Cape d'Aguilar (Table 1; Figure 2a) or Wah Fu (Table 1; Figure $2 b$ ).

\section{Semi-artificial environment study}

On artificial slabs, both temperature and desiccation rate were significantly lower (by $\sim 20^{\circ} \mathrm{C}$ and $30 \%$ ) in the shaded as compared to the open or procedural control treatments (Table 2). No significant difference was, however, found between the percentages of snails aggregating in different treatments (Table 2), although the mean percentage of snails aggregating was higher, by almost $20 \%$, in the shaded treatment as compared to the open treatment, and $>10 \%$ higher in the shaded treatment than in the procedural control (Figure 3). Snails stopped moving in the open treatments $\sim 15-20 \mathrm{~min}$ before the covered treatments, which equates to changes in foraging time of $\sim 50$ model timesteps.

\section{Computer simulation}

Simulations of real shores (equivalent to the natural shore study observations detailed above) were run 500 times for each treatment to ensure a reliable estimate of the true mean value ( $\mathrm{SE}<0.5 \%$ of mean). The initial simulation predicted a mean of $41.8 \%$ of snails in aggregations (Figure $4 \mathrm{a}$ ). This percentage decreased to $25.1 \%$ when the time of the simulation was reduced to 350 timesteps, but increased to levels similar to those initially recorded $(42.1 \%)$ when both the time and decision parameter values were altered (Figure 4a).

The simulations of the slab experiments were run 2000 times for each treatment to ensure a reliable estimate of the true mean value ( $\mathrm{SE}<0.5 \%$ of mean). The baseline conditions, in this case indicative of the coolest conditions (shaded treatment), showed a mean of $48 \%$ of snails in aggregations (Figure $4 \mathrm{~b}$ ). Decreasing the time of movement resulted in a large reduction in the proportion of aggregating snails (to $30 \%$ ). Altering the parameters of the behavioural rules ( $a$ and $b$ ), as well as reducing the time of movement, gave an intermediate mean value of $40 \%$ of snails in aggregations (Figure 4b).

\section{Discussion}

During hot, desiccating conditions, individual-level snail behaviour changes from that exhibited in cooler, less desiccating conditions. The time snails spend moving decreases, probably because the rock surface dries faster [11]. This should give snails

Table 1. Summary of comparisons using nested ANOVA to determine variation in desiccation of cotton wool balls and aggregation behaviour of littorinid snails during different environmental conditions (Factor = Temperature, fixed with 2 levels, Hot or Cool Days) on three replicate occasions (Factor = Day, random with 3 levels).

\begin{tabular}{|c|c|c|c|c|c|}
\hline Comparison & Shore & Factor & $F$ & d.f. & $p$ \\
\hline \multirow{2}{*}{$\begin{array}{l}\text { Desiccation of cotton wool balls at different } \\
\text { temperatures }\end{array}$} & Cape d'Aguilar & Day(Temperature) & 2.50 & 8,20 & 0.043 \\
\hline & & Temperature & 96.00 & 1,20 & $<0.001$ \\
\hline \multirow{2}{*}{$\begin{array}{l}\text { Aggregation behaviour at different temperatures } \\
\text { and low wave action }\end{array}$} & Cape d'Aguilar & Day(Temperature) & 0.40 & 4,54 & 0.806 \\
\hline & & Temperature & 3.99 & 1,54 & 0.166 \\
\hline \multirow{2}{*}{$\begin{array}{l}\text { Aggregation behaviour at different temperatures } \\
\text { and high wave action }\end{array}$} & Wah Fu & Day(Temperature) & 0.39 & 4,54 & 0.390 \\
\hline & & Temperature & 5.22 & 1,54 & 0.084 \\
\hline
\end{tabular}

Values in bold indicate significant differences between treatments $(p<0.05)$. For all comparisons: Levene's test for homogeneity of variance $p>0.05$, not significant. doi:10.1371/journal.pone.0022743.t001 
A

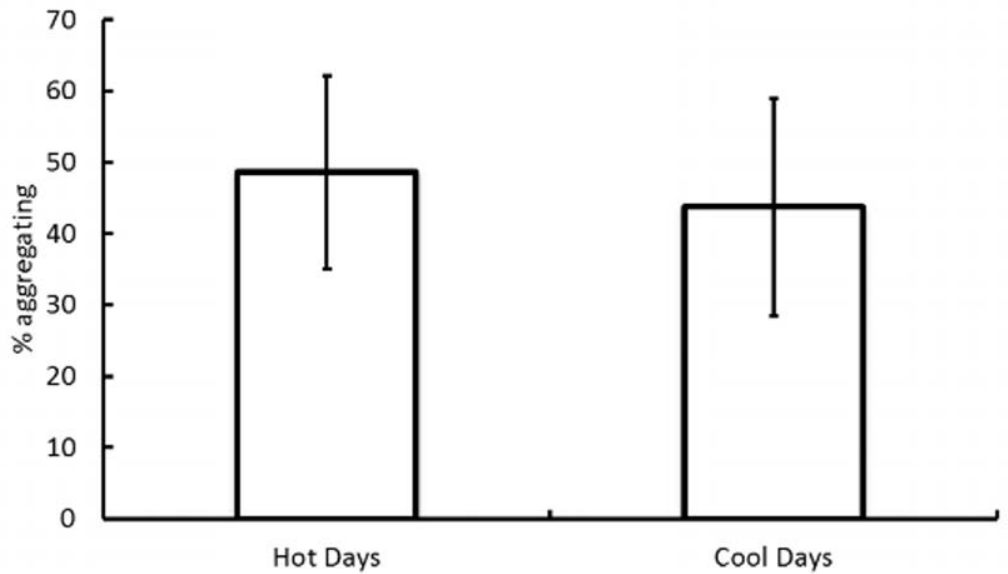

B

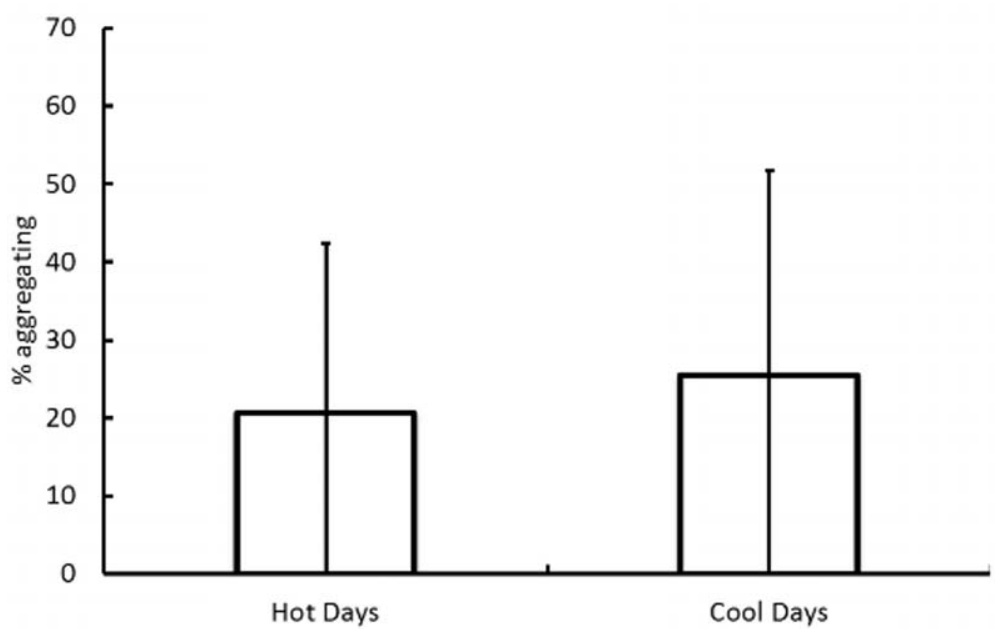

Figure 2. Aggregations on Hot and Cool days. Mean ( $\pm S D, n=30$ ) percentage of snails aggregating on Hot Days $\left(>35^{\circ} \mathrm{C}\right)$ and $\mathrm{Cool}$ Days $\left(<28^{\circ} \mathrm{C}\right)$ at (a) Cape d'Aguilar and (b) Wah Fu.

doi:10.1371/journal.pone.0022743.g002

less time to locate other individuals and form aggregations, therefore fewer or smaller aggregations should be formed, i.e. an individual-level change in behaviour has a direct effect on selforganised behaviour [11]. This appears to be a sub-optimal

Table 2. Summary of comparisons using ANOVA and subsequent SNK tests to determine differences between surface temperature, desiccation and sheltering behaviour of littorind snails on marble rock slabs with different treatments (open to full sunlight, shaded with a roof and a procedural control).

\begin{tabular}{llllll}
\hline Comparison & $F$ & d.f. & $P$ & SNK tests & \\
\hline Temperature & 210.8 & 2,27 & $<\mathbf{0 . 0 0 1}$ Open $=$ & $\begin{array}{l}\text { Procedural } \\
\text { control }>\end{array}$ & Shaded \\
Desiccation & 79.4 & 2,27 & $<\mathbf{0 . 0 0 1}$ Open $=\begin{array}{l}\text { Procedural } \\
\text { control }>\end{array}$ & Shaded \\
$\begin{array}{lllll}\text { Aggregation } \\
\text { behaviour }\end{array}$ & 0.98 & 2,27 & 0.388 & & \\
\hline
\end{tabular}

Values in bold indicate significant differences between treatments $(p<0.05)$. For all comparisons: Levene's test for homogeneity of variance $p>0.05$, not significant.

doi:10.1371/journal.pone.0022743.t002 behaviour, as aggregation reduces desiccation [10], and the consequences of not aggregating on highly desiccating days should be greater than on cooler days. This theory is supported by results from the semi-artificial environment studies and computer simulations of those studies, indicating there are clear differences in the self-organised behaviour as a result of behavioural changes

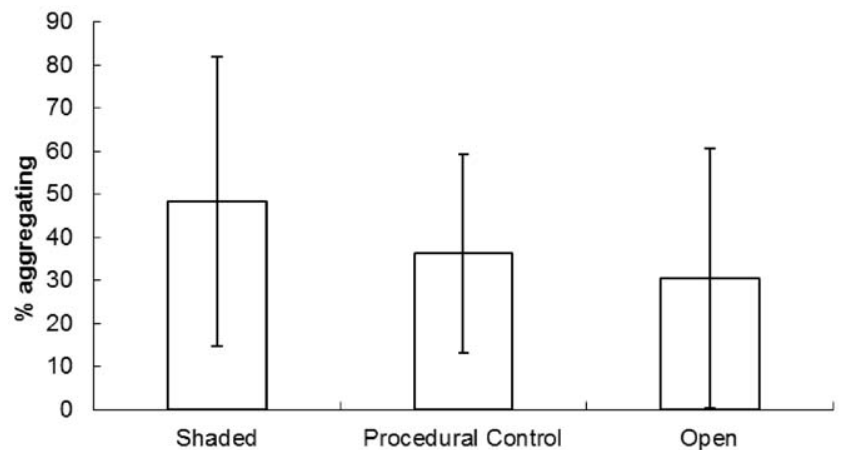

Figure 3. Aggregations in semi-artificial environments. Mean $( \pm$ $\mathrm{SD}, \mathrm{n}=10$ ) percentage of snails aggregating in semi-artificial environments (marble rock slabs) under three different treatments (Shaded, procedural control and open).

doi:10.1371/journal.pone.0022743.g003 

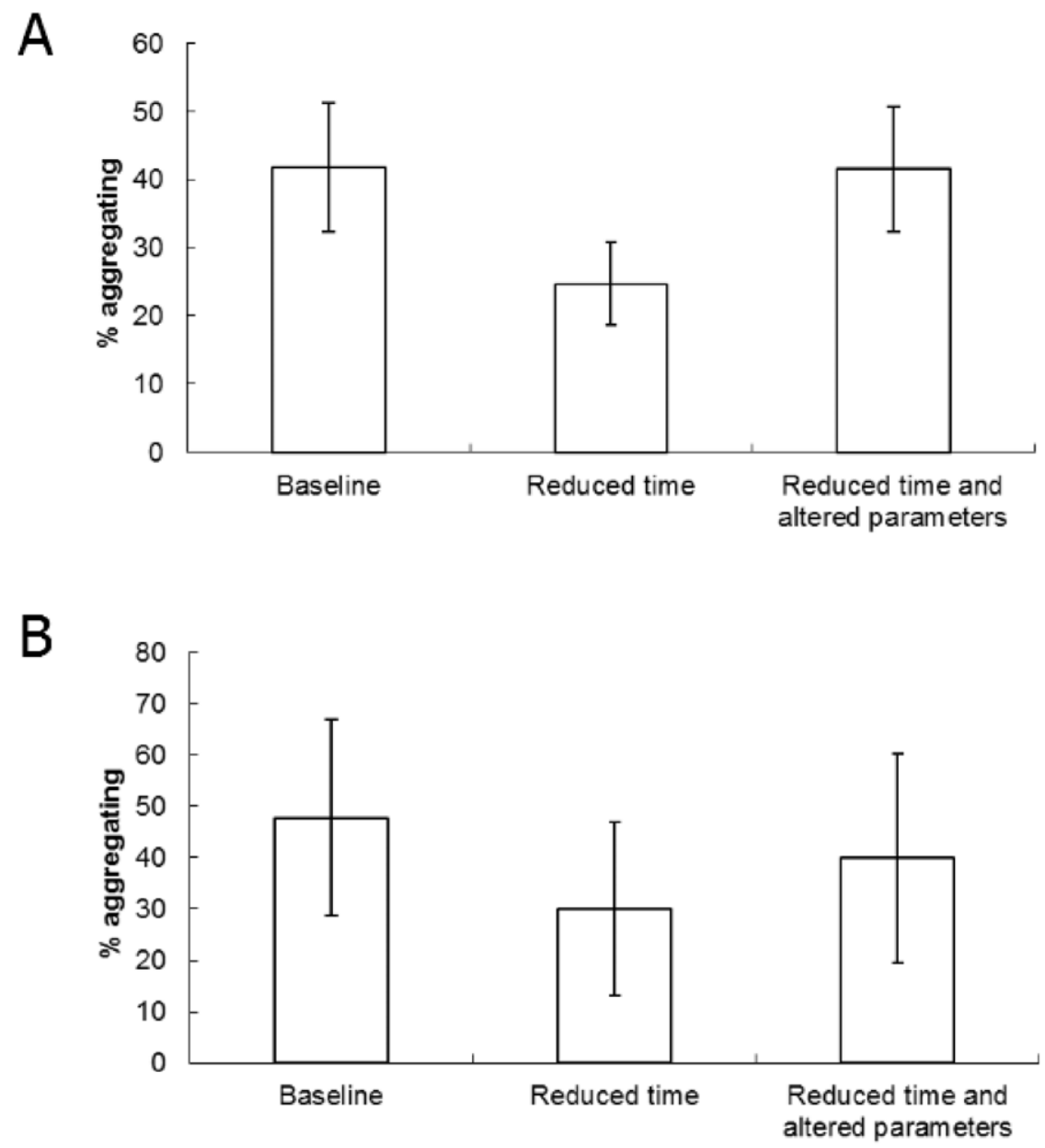

Figure 4. Aggregations in simulated experiments. Mean ( $\pm S D, n=500$ or 2000) percentage of snails aggregating in (a) simulated shore experiments and (b) simulated semi-artificial environment experiments. doi:10.1371/journal.pone.0022743.g004

at the individual level in this situation. However, results from fully natural environments showed no change in the collective behaviour, despite differences in desiccation between shaded and unshaded, and hot and cold days, being broadly similar. This was true of directly recorded results from the shore, as well as simulations of the snails from the natural shore environment (essentially the inclusion of mucus trails that were persistent between tidal cycles). The lack of change in the percentage of snails aggregating demonstrates that in natural environments, selforganised behaviours can be robust to changes in individual-level behaviour.

Clear differences were found between the two natural shore sites investigated, with Cape d'Aguilar having a much higher proportion of aggregating snails than Wah Fu. However, this is likely to be due to crevice abundance at the two sites (Wah Fu having numerous small crevices [10]), rather than due to differences in behaviour of the snails or other environmental variables. Presence of ample small refuges have been shown to reduce aggregation behaviour [18]. Hence, in this study, the lack of relative change between environmental conditions is of more interest than the absolute values of aggregation at different sites.

In evolutionary terms, self-organisation, at least in the case of littorinid snails, can overcome the need for complex sensory and cognitive systems that deal with changing environments, which can be costly to develop [19]. While constraints in sensory and cognitive systems have previously been shown to produce nonperfect behaviours (those that do not correspond to a predicted optimal value, such as sex ratio [20-22]), it may be that in some cases, simple, low complexity sensory systems are able to perform better in self-organising systems than in systems where no selforganisation occurs. In this study, by simply sensing rock dryness, and having behaviours governed by this single parameter, foraging time will be increased where possible (i.e. in cooler conditions) and aggregation levels can remain high in both cool and hot conditions. Essentially, self-organisation allows the snails to avoid some of the developmental costs of complex sensory systems and still optimise both their feeding and sheltering behaviours.

In terms of application to other studies of self-organising systems, the results suggest that tests of the effectiveness of collective behaviour could be limited if they are conducted in simplified environments (such as the laboratory), or in computer simulations with little regard to the natural environment. This supports much work, from sub-organismal, neuroethological studies to community or global level studies [e.g. 23-25], suggesting that an integrated understanding of interactions of organisms in their environment is important in elucidating the true functional or adaptive benefits of behaviours and other ecological processes. 


\section{Acknowledgments}

We are grateful to the anonymous reviewers for their helpful comments on the manuscript and to the Agriculture, Fisheries and Conservation Department, HKSAR Government, for permission to work in the Cape d'Aguilar Marine Reserve.

\section{References}

1. Camazine S, Deneubourg JL, Franks NR, Sneyd J, Theraulaz G, et al. (2001) Self-organization in biological systems. Princeton: Princeton University Press. $560 \mathrm{p}$.

2. Bonabeau E, Dorigo M, Theraulaz G (1999) Swarm intelligence: from natural to artificial systems. Oxford: Oxford University Press. 320 p.

3. Detrain C, Deneubourg JL (2006) Self-organized structures in a superorganism: do ants "behave" like molecules? Phys Life Rev 3; 162: 187.

4. Couzin ID, Franks NR (2002) Self-organized lane formation and optimized traffic flow in army ants. Proc Roy Soc Lond 270: 139-46.

5. Dussutour A, Fourcassie V, Helbing D, Deneubourg JL (2004) Optimal traffic organization in ants under crowded conditions. Nature 428: 70-73.

6. Boyden CR, Zeldis JR (1979) Preliminary observations using attached microphonic sensors to study feeding behaviour of an intertidal limpet. Estuarine Coastal Mar Sci 9: 759-769.

7. Santini G, DePirro M, Chelazzi G (1999) In-situ and laboratory assessment of heart rate in a Mediterranean limpet using a non-invasive technique. Physiol Biochem Zool 72: 198-204.

8. Little C, Stirling P (1985) Patterns of foraging activity in the limpet Patella vulgate L. - A preliminary study. J Exp Mar Biol and Ecol 89: 283-296.

9. Moran MJ (1985) The timing and significance of sheltering and foraging behaviour of the predatory intertidal gastropod Morula maginalba Blainville (Muricidae). J Exp Mar Biol and Ecol 93: 103-114.

10. Stafford R (2002) The role of environmental stress and physical and biological interactions on the ecology of high shore littorinids in a temperate and a tropical region. PhD thesis, University of Sunderland, UK.

11. Stafford R, Davies MS (2005) Examining refuge location mechanisms in intertidal snails using artificial life simulation techniques. Lecture Notes Artif Intell 3630: 520-529.

12. Stafford R, Davies MS, Williams GA (2007) Computer simulations of high shore littorinids predict small-scale spatial and temporal distribution patterns on real rocky shores. Mar Ecol Prog Ser 342: 151-161.

\section{Author Contributions}

Conceived and designed the experiments: MSD GAW RS. Performed the experiments: MSD GAW RS. Analyzed the data: MSD GAW RS. Contributed reagents/materials/analysis tools: MSD GAW RS. Wrote the paper: MSD GAW RS. Wrote the code for the model: RS.

13. Stafford R, Davies MS, Williams GA (2008) Self-organization of intertidal snails facilitates evolution of aggregation behavior. Artificial Life 14: 409-423.

14. Stafford R, Davies MS (2004) Temperature and desiccation do not affect aggregation behaviour in high shore littorinids in north-east England. J Negative Results: Ecol Evol Biol 1: 16-20.

15. Chapman MG, Underwood AJ (1996) Influences of tidal conditions, temperature and desiccation on patterns of aggregation of the high-shore periwinkle Littorina unifasciata in New South Wales, Australia. J Exp Mar Bio Ecol 196: 213-237.

16. Davies MS, Knowles AJ, Edmondston P, Hutchinson N (1997) The use of a commercial insect-trapping compound to maintain grazer densities on rocky shores. Trans Nat Hist Soc Northumbria 57: 185-189.

17. Williams GA, Morritt D (1995) Habitat partitioning and thermal tolerance in a tropical limpet, Cellana grata on a tropical rocky shores. Mar Ecol Prog Ser 124: 89-103.

18. Cartwright SR (2010) Facilitation of intertidal species against environmental stress by barnacles in tropical Hong Kong. PhD Thesis, The University of Hong Kong, HK.

19. Isler K, van Schaik CP (2006) Metabolic costs of brain size evolution. Biol Lett 2: 557-560.

20. Herre EA (1987) Optimality, plasticity and selective regime in fig wasp sex ratios. Nature 329: 627-629.

21. Parker GA, Maynard Smith J (1990) Optimality theory in evolutionary biology. Nature 348: 27-33.

22. West SA, Sheldon BC (2002) Constraints in the evolution of sex ratio adjustment. Science 295: 1685-1689.

23. O'Carroll DC, Bidwell NJ, Laughlin SB, Warrant EJ (1996) Insect motion detectors matched to visual ecology. Nature 382: 63-66.

24. Stafford R, Santer RD, Rind FC (2007) The role of behavioural ecology in the design of bio-inspired technology. Animal Behaviour 74: 1813-1819.

25. Lovelock JE (2003) Gaia and emergence. Climatic Change 57: 1-3. 